\title{
Antithrombotic therapy in high-risk patients after percutaneous coronary intervention; study design, cohort profile and incidence of adverse events
}

\author{
R. H. Olie · P. E. J. van der Meijden · M. J. A. Vries · L. Veenstra · A. W. J. van 't Hof · J. M. ten Berg • \\ Y. M. C. Henskens · H. ten Cate
}

Accepted: 18 June 2021 / Published online: 1 September 2021

(C) The Author(s) 2021

\begin{abstract}
Background Patients with multiple clinical risk factors are a complex group in whom both bleeding and recurrent ischaemic events often occur during treatment with dual/triple antithrombotic therapy after percutaneous coronary intervention. Decisions on optimal antithrombotic treatment in these patients are challenging and not supported by clear guideline recommendations. A prospective observational cohort study was set up to evaluate patient-related factors, platelet reactivity, genetics, and a broad spectrum of biomarkers in predicting adverse events in these high-risk patients. Aim of the current paper is to present the study design, with a detailed description of the cohort as a whole, and evaluation of bleeding and ischaemic outcomes during follow-up, thereby facilitating future research questions focusing on specific data provided by the cohort.

Methods We included patients with $\geq 3$ predefined risk factors who were treated with dual/triple antithrombotic therapy following PCI. We performed a wide
\end{abstract}

Data sharing statement: Collaboration is welcomed and data sharing can be agreed upon. The corresponding author can be contacted.

\footnotetext{
Supplementary Information The online version of this article (https://doi.org/10.1007/s12471-021-01606-2) contains supplementary material, which is available to authorized users.

R. H. Olie $(\varangle) \cdot$ P. E. J. van der Meijden $\cdot$ H. ten Cate Thrombosis Expertise Centre, Heart and Vascular Centre, Department of Internal Medicine, Maastricht University Medical Centre (MUMC+), Maastricht, The Netherlands Renske.olie@mumc.nl

R. H. Olie · P. E. J. van der Meijden · M. J. A. Vries · A. W. J. van 't Hof · Y. M. C. Henskens · H. ten Cate

Cardiovascular Research Institute Maastricht (CARIM),

Maastricht University, Maastricht, The Netherlands
}

\section{What's new?}

- Increasingly, complex patients are treated with percutaneous coronary intervention (PCI), leading to a group of high-risk patients with multiple clinical risk factors being treated with dual or even triple antithrombotic therapy following PCI.

- These complex patients are frequently underrepresented in large clinical trials, and thus there is little evidence on optimal treatment.

- This cohort study was designed to evaluate patient-related factors, residual platelet reactivity, a broad spectrum of biomarkers, and bleeding questionnaires in predicting adverse events.

- Almost half of patients had at least one bleeding event during 6-12 months of dual/triple antithrombotic therapy and in $13.2 \%$ major adverse cardiovascular events occurred.
L. Veenstra · A. W. J. van 't Hof

Department of Cardiology, MUMC+, Maastricht, The Netherlands

J. M. ten Berg

Department of Cardiology, St Antonius Hospital, Nieuwegein, The Netherlands

Y. M. C. Henskens

Central Diagnostic Laboratory, MUMC+, Maastricht, The Netherlands

L. Veenstra · A. W. J. van 't Hof

Department of Cardiology, Zuyderland Medical Centre, Heerlen, The Netherlands 
range of haemostatic tests and collected all ischaemic and bleeding events during 6-12 months follow-up. Results We included 524 high-risk patients who underwent PCI within the previous $1-2$ months. All patients used a P2Y12 inhibitor (clopidogrel $n=388$, prasugrel $n=61$, ticagrelor $n=75)$ in combination with aspirin $(n=397)$ and/or anticoagulants $(n=160)$. Bleeding events were reported by 254 patients (48.5\%), necessitating intervention or hospital admission in 92 patients $(17.5 \%)$. Major adverse cardiovascular events (myocardial infarction, stroke, death) occurred in 69 patients $(13.2 \%)$.

Conclusion The high risk for both bleeding and ischaemic events in this cohort of patients with multiple clinical risk factors illustrates the challenges that the cardiologist faces to make a balanced decision on the optimal treatment strategy. This cohort will serve to answer several future research questions about the optimal management of these patients on dual/ triple antithrombotic therapy, and the possible value of a wide range of laboratory tests to guide these decisions.

Keywords Anticoagulation - Antiplatelet therapy · Antithrombotic treatment - Percutaneous coronary intervention · Coronary artery disease · Bleeding

\section{Introduction}

Percutaneous coronary intervention (PCI) is the treatment of choice in most patients with acute coronary syndrome (ACS) and frequently performed in patients with chronic coronary artery syndrome [1]. As results with PCI have improved due to better stents and antithrombotic treatment, increasingly complex patient populations are treated. International guidelines recommend a period of 6-12 months of dual antiplatelet therapy (DAPT) after PCI, sometimes in combination with oral anticoagulation if other comorbidities (e.g. atrial fibrillation) demand to do so [1,2]. Thus, cardiologists are more and more challenged in treating complex, high-risk patients with dual or triple antithrombotic therapy. With the introduction of the more potent P2Y12 inhibitors prasugrel and ticagrelor next to clopidogrel $[3,4]$, and the widespread availability of direct oral anticoagulants (DOACs) next to vitamin $\mathrm{K}$ antagonists (VKAs), physicians are enabled to select different and individualised treatment regimens. Although evidence on optimal treatment exists for most patients, "high-risk" patients with multiple clinical risk factors (in whom both bleeding complications and recurrent ischaemic events occur more often) remain a challenging group. However, these patients are frequently excluded from or underrepresented in the large clinical trials, and although several bleeding risk scores have been developed, these scores have not been specifically validated in high-risk subjects [5].
This cohort study was designed to provide evidence on predictors, safety and outcome in a relevant subgroup of high-risk patients, and is part of an ongoing clinical care pathway. Patients are managed based on current international guidelines during the 6-12 month period of combined antithrombotic treatment following PCI (either with ACS indication or elective procedure). The clinical care pathway involves the assessment of the risk balance between thrombosis and bleeding prevention by identification and, if possible, removing such risk enhancing factors. In this study, we aim to evaluate patient-related factors, on-treatment platelet reactivity, biomarkers and bleeding questionnaires in predicting adverse events in high-risk patients. Future goals are to optimise the therapeutic windows of platelet functions tests (PFTs) for this specific group and to validate and/or develop risk estimation tools for prediction of bleeding complications in a population with multiple clinical risk factors.

The aim of the current cohort profile paper is to present a detailed description of the cohort as a whole, with evaluation of bleeding and ischaemic outcomes during follow-up, thereby facilitating future research questions focusing on specific data provided by the cohort.

\section{Methods}

This prospective observational cohort study is conducted at the Thrombosis Expertise Centre in the Maastricht University Medical Centre (MUMC+) in the Netherlands. The medical ethics committee (METC) of the MUMC+ approved this study as an evaluation of patient care analysis (NL38767.068.11, METC number 11-2-096), and all patients provided written informed consent.

\section{Study population}

Patients treated with PCI or coronary thrombolysis between May 2014 and May 2019 were screened for the presence of 3 or more predefined risk factors (Tab. 1) by one dedicated interventional cardiologist. These patients, all being treated with either DAPT or a combination of antiplatelet therapy with oral anticoagulants, were referred to a specialised outpatient clinic within the Thrombosis Expertise Centre for assessment of their bleeding risks and ischaemic risks. After informed consent was obtained, data on patient history, medication and comorbidities were collected, and blood was drawn for extensive haemostatic and genetic testing. Treatment decisions and subsequent medication switches were not part of the study, and initiated on the treating physician's discretion, although all this information on medication switches was collected in the dataset. 
Table 1 Inclusion and exclusion criteria

\begin{tabular}{|c|c|}
\hline $\begin{array}{l}\text { Inclusion } \\
\text { criteria }\end{array}$ & Definition \\
\hline $\begin{array}{l}\mathrm{PCl} 30-90 \text { days be- } \\
\text { fore study inclusion }\end{array}$ & Elective or emergency procedure \\
\hline $\begin{array}{l}\text { Dual/triple anti- } \\
\text { thrombotic therapy }\end{array}$ & Including a P2Y12 inhibitor \\
\hline \multirow{14}{*}{$\begin{array}{l}\text { Classified as 'vul- } \\
\text { nerable' by } \geq 3 \\
\text { predefined risk } \\
\text { factors: }\end{array}$} & Age $\geq 75$ years \\
\hline & Female gender \\
\hline & Renal dysfunction (MDRD-eGFR $\leq 60 \mathrm{ml} / \mathrm{min}$ ) \\
\hline & Body weight $\leq 60 \mathrm{~kg}$ \\
\hline & Hypertension (previously diagnosed, or on medication) \\
\hline & Diabetes mellitus \\
\hline & $\begin{array}{l}\text { Anaemia }(\mathrm{Hb}<8.2 \mathrm{mmol} / \mathrm{l} \text { for } \mathrm{men},<7.3 \mathrm{mmol} / \mathrm{l} \text { for } \\
\text { women) }\end{array}$ \\
\hline & Previous stroke \\
\hline & Previous major bleeding \\
\hline & Liver dysfunction (known hepatitis or transplant) \\
\hline & History of gastric/duodenal ulcers \\
\hline & Daily use of NSAIDs or SSRIs \\
\hline & $\begin{array}{l}\text { Triple antithrombotic therapy (DAPT + oral anti- } \\
\text { coagulants) }\end{array}$ \\
\hline & $\begin{array}{l}\text { Previous in-stent thrombosis or high risk coronary } \\
\text { stent } \\
\text { ( } \geq 3 \text { lesions treated, total stent length }>60 \mathrm{~mm} \text {, last } \\
\text { remaining vessel, or left main coronary artery stenting) }\end{array}$ \\
\hline $\begin{array}{l}\text { Exclusion } \\
\text { criteria }\end{array}$ & Definition \\
\hline $\begin{array}{l}\text { Known platelet } \\
\text { function disorders }\end{array}$ & Previously diagnosed platelet function disorders \\
\hline $\begin{array}{l}\text { Recent coronary } \\
\text { intervention }\end{array}$ & $\mathrm{PCl}$ or $\mathrm{CABG} \leq 7$ days \\
\hline $\begin{array}{l}\text { Recent new is- } \\
\text { chaemic event }\end{array}$ & ACS or stroke $\leq 7$ days \\
\hline $\begin{array}{l}\text { Signs of active } \\
\text { infection }\end{array}$ & $\begin{array}{l}\text { Fever, antibiotic treatment or hospital admission } \\
\text { during laboratory assessment of platelet function }\end{array}$ \\
\hline $\begin{array}{l}\text { Medication non- } \\
\text { compliance }\end{array}$ & $\begin{array}{l}\text { Confirmed non-compliance in antithrombotic medi- } \\
\text { cation by patient interview or pharmacy dispensing }\end{array}$ \\
\hline \multicolumn{2}{|c|}{$\begin{array}{l}P C / \text { percutaneous coronary intervention, } M D R D \text {-eGFR Modification of Diet } \\
\text { in Renal Disease- estimated glomerular filtration rate, } H b \text { Haemoglobin, } \\
\text { NSAIDs non-steroidal anti-inflammatory drugs, SSRIs selective serotonin } \\
\text { reuptake inhibitors, DAPT dual antiplatelet therapy, } C A B G \text { coronary artery } \\
\text { bypass graft, } A C S \text { acute coronary syndrome }\end{array}$} \\
\hline
\end{tabular}

\section{Clinical care pathway}

The clinical care pathway is illustrated in Fig. 1. At the first visit (1-2 months after PCI) information on medical history, medication and compliance was collected. A thorough history on both previous and current minor and major bleeding events was taken, using the International Society on Thrombosis and Haemostasis Bleeding Assessment Tool (ISTH-BAT) [6]. During all three study visits, bleeding events were recorded using the definition of the Bleeding Academic Research Consortium (BARC), which contains unified and validated bleeding criteria [7, 8]. Finally, blood was drawn for extensive testing, including PFTs as described below. At the second visit 6 months post-PCI, we collected information on ischaemic and bleeding events, checked the medication, compliance and side effects. Standard laboratory evaluation during this second visit was performed in the first 200 included patients, and in further patients additional testing was only performed if indicated by clinical clues. If the P2Y12 inhibitor was prescribed for more than 6 months, information on bleeding and ischaemic events was collected during an additional telephone call at 12 months. Thus, depending on duration of combination therapy, the total follow-up time was 6 to 12 months.

\section{Laboratory evaluation}

Information on blood collection and detailed description of all performed laboratory tests is described in the Supplemental data. In short, laboratory evaluation consisted of total blood count, renal function, routine haemostatic parameters, rotational thromboelastometry and thrombin generation assays, and DOAC levels if applicable. On-treatment platelet reactivity was measured using three different platelet function tests with multiple agonists: VerifyNow, Multiple Electrode Impedance Aggregometry by Multiplate, and Light Transmission Aggregometry (LTA). Finally, samples were stored to measure coagulation factors, markers of fibrinolysis, and to perform additional genetic testing (e.g. CYP2C19 polymorphisms).

\section{Endpoints}

The primary endpoint was defined as any bleeding ( $\geq$ BARC type 1 ) according to the Bleeding Academic Research Consortium criteria [7, 8]. The primary ischaemic endpoint was defined as a composite of myocardial infarction [9], ischaemic stroke (including transient ischaemic attack), and all-cause death. Other ischaemic endpoints include coronary revascularisation, peripheral artery disease revascularisation and venous thromboembolism.

\section{Statistical analysis}

Continuous variables are expressed as either mean \pm standard deviation for normally distributed traits or median with interquartile range (IQR) otherwise. Categorical variables are expressed as counts and percentages. Statistical analyses were performed with IBM SPSS statistics version 25.0.

\section{Results}

Initially 560 patients were included in the study and informed consent was obtained. However, subsequently 36 patients had to be excluded for various reasons, and therefore, the final study population consisted of 524 high-risk patients (Fig. 2). Baseline characteristics of the study population are shown in Tab. 2. Mean age is $74.7 \pm 8.7$ years and patients have 
Fig. 1 Timeline of the clinical care pathway

Fig. 2 Flowchart of study inclusion and follow-up. $\mathrm{PCl}$ percutaneous coronary intervention
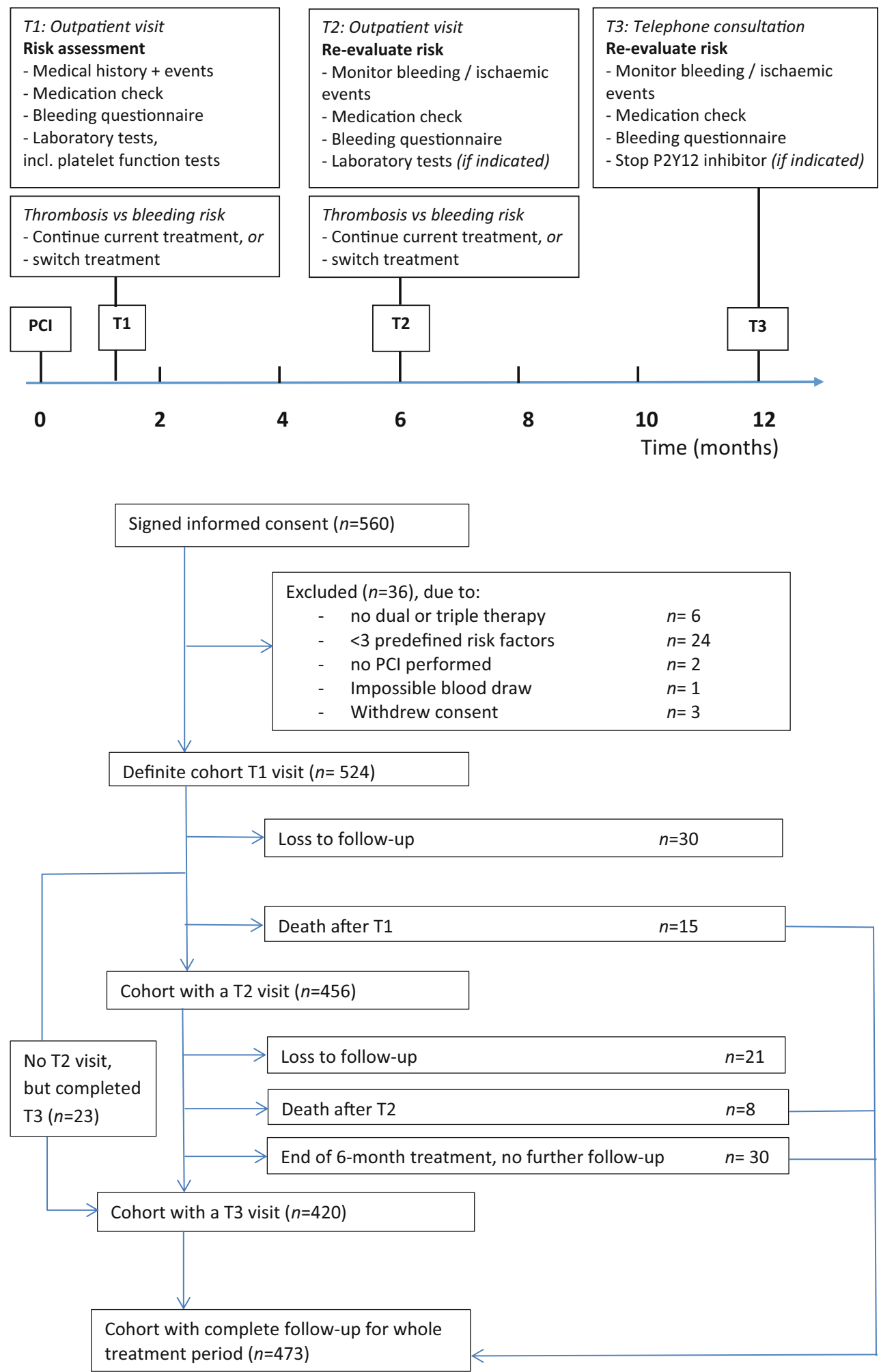

a median number of 4 (IQR 3-5) predefined clinical risk factors. At the first study visit (T1), 46 (37-59) days post-PCI, all patients used a P2Y12 inhibitor (clopidogrel $n=388$, prasugrel $n=61$, ticagrelor $n=75$ ) according to the inclusion criteria, in combination with aspirin $(n=392)$ and/or anticoagulants $(n=160)$. In most patients $(n=364,69.4 \%)$ the antithrombotic strategy consisted of dual antiplatelet therapy, whereas $17.0 \%$ $(n=89)$ used a P2Y12 inhibitor in combination with anticoagulants, and $13.5 \%(n=71)$ had a strategy with triple therapy for at least one month. 


\section{Advertisement placed here.}

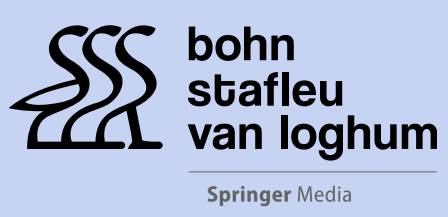

Houten 2021 


\section{Advertisement placed here.}

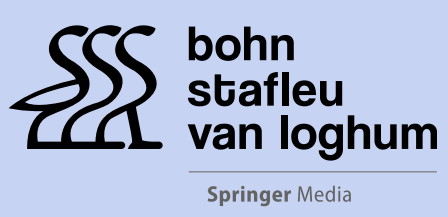

Houten 2021 
Table 2 Baseline characteristics of the full cohort $(n=524)$

\begin{tabular}{|c|c|}
\hline Variable & $\begin{array}{l}N(\%), \text { or } \\
\text { mean } \pm \text { SD }\end{array}$ \\
\hline Age, years & $74.7 \pm 8.7$ \\
\hline Male & $302(57.6)$ \\
\hline Body mass index, $\mathrm{kg} / \mathrm{m}^{2} \mathrm{a}$ & $27.4 \pm 4.6$ \\
\hline Current smoking ${ }^{b}$ & $72(13.7)$ \\
\hline Alcohol consumption $\geq 7$ drinks/week ${ }^{c}$ & $99(18.9)$ \\
\hline PPI use at inclusion & 441 (84.2) \\
\hline \multicolumn{2}{|l|}{ Predefined risk factors } \\
\hline Number of predefined risk factors, median [min-max] & $4[3-9]$ \\
\hline - Age $\geq 75$ years & $318(60.7)$ \\
\hline - Women & $222(42.4)$ \\
\hline - Weight $\leq 60 \mathrm{~kg}$ & $60(11.5)$ \\
\hline - Diabetes mellitus & $186(35.5)$ \\
\hline - Hypertension & $448(85.5)$ \\
\hline - Anaemia & $204(38.9)$ \\
\hline - Renal dysfunction (MDRD-eGFR <60) & $313(59.7)$ \\
\hline - Liver failure & $2(0.4)$ \\
\hline - History of gastric/duodenal ulcers & $61(11.6)$ \\
\hline - Previous major bleeding & $65(12.4)$ \\
\hline - Previous stroke & $138(26.3)$ \\
\hline - Use of NSAIDs & $21(4.0)$ \\
\hline - Use of SSRIs & $31(5.9)$ \\
\hline - Triple antithrombotic therapy & $71(13.5)$ \\
\hline - High-risk PCl & $47(9.0)$ \\
\hline \multicolumn{2}{|l|}{ Index $\mathrm{PCl}$} \\
\hline Acute coronary syndrome & 333 (63.5) \\
\hline Elective procedure & $191(36.5)$ \\
\hline Radial access & $232(44.3)$ \\
\hline \multicolumn{2}{|l|}{ Number of stents } \\
\hline - 0 (DEB, POBA, thrombolysis) & $29(5.5)$ \\
\hline-1 & $352(67.2)$ \\
\hline-2 & $98(18.7)$ \\
\hline-3 & $45(8.6)$ \\
\hline \multicolumn{2}{|l|}{ Type of stent/procedure } \\
\hline - DES & $490(93.5)$ \\
\hline - BMS & $4(0.8)$ \\
\hline - Absorb & $1(0.2)$ \\
\hline - Drug-eluting balloon & $12(2.3)$ \\
\hline - POBA +/- thrombus aspiration & $14(2.7)$ \\
\hline - Thrombolysis & $3(0.6)$ \\
\hline \multicolumn{2}{|l|}{ Cardiovascular history } \\
\hline Prior PCl & $197(37.6)$ \\
\hline Prior CABG & $106(20.2)$ \\
\hline Prior Stroke & $138(26.3)$ \\
\hline Atrial fibrillation & $138(26.3)$ \\
\hline Peripheral artery disease & $76(14.5)$ \\
\hline Prior venous thromboembolism & $39(7.4)$ \\
\hline \multicolumn{2}{|l|}{ Previous history } \\
\hline Active malignancy & $24(4.6)$ \\
\hline Peptic ulcer disease & $61(11.6)$ \\
\hline \multicolumn{2}{|l|}{ Treatment at first study visit } \\
\hline P2Y12 inhibitor & $524(100.0)$ \\
\hline - Clopidogrel & $388(74.0)$ \\
\hline
\end{tabular}

Table 2 (Continued)

\begin{tabular}{lr} 
Variable & $\begin{array}{c}N(\%), \text { or } \\
\text { mean } \pm \text { SD }\end{array}$ \\
- Prasugrel & $61(11.6)$ \\
\hline - Ticagrelor & $75(14.3)$ \\
\hline Aspirin & $392(74.8)$ \\
\hline Vitamin K antagonist & $91(17.3)$ \\
\hline DOAC & $68(13.0)$ \\
- Apixaban & $20(3.8)$ \\
- Rivaroxaban & $34(6.5)$ \\
- Edoxaban & $4(0.8)$ \\
- Dabigatran & $10(1.9)$ \\
LMWH & $1(0.2)$ \\
Dipyridamole & $2(0.4)$ \\
\hline
\end{tabular}

Combination strategies

Dual antiplatelet treatment (DAPT) 364 (69.4)

- For 6 months $62(11.8)$

- For 12 months $302(57.6)$

P2Y12 inhibitor with VKA/DOAC/LMWH $89(17.0)$

Initial triple therapy ${ }^{\dagger} \quad 71(13.5)$

- For 1 month 64 (12.2)

- For 3-6 months $7(1.4)$

Laboratory test (reference range) Mean $+/-S D$

Haemoglobin

- Male $(8.2-11.0 \mathrm{mmol} / \mathrm{l}) \quad 8.4 \pm 1.1$

- Female $(7.3-9.7 \mathrm{mmol} / \mathrm{l}) \quad 8.0 \pm 0.9$

Haematocrit

- Male $(0.42-0.52 \mathrm{l} / \mathrm{I}) \quad 0.41 \pm 0.05$

- Female $(0.36-0.48 \mathrm{I} / \mathrm{I}) \quad 0.39 \pm 0.04$

\begin{tabular}{l|l} 
MCV (80-100 fl) & $91.7 \pm 5.8$
\end{tabular}

Platelet count, $\left(150-35010^{9} / \mathrm{l}\right) \quad 261 \pm 78$

MPV (80-100 fl) $10.3 \pm 0.9$

$\begin{array}{ll}\text { PT }(9.9-11.5 \mathrm{sec})^{\mathrm{g}} & 10.7 \pm 0.5\end{array}$

$\begin{array}{ll}\text { APTT }(23-32 \mathrm{sec})^{9} & 26.2 \pm 2.1\end{array}$

Fibrinogen $(1.7-4.0 \mathrm{~g} / \mathrm{l}) \quad 3.7 \pm 0.9$

Creatinine $(50-100 \mu \mathrm{mol} / \mathrm{l}) \quad 116.6 \pm 74.9$

$\begin{array}{ll}\left.\text { MDRD-eGFR (ml/min/ } / 1.73 \mathrm{~m}^{2}\right) & 57.1 \pm 21.0\end{array}$

Platelet function test (cut-off values for $L P R$ and $H P R^{\mathrm{h}}$ )

Multiplate ADP (19-46 AU) ${ }^{\text {d }} \quad 47.7 \pm 23.2$

LTA ADP (20-59\% max aggr) ${ }^{\text {e }} \quad 41.4 \pm 16.5$

VerifyNow P2Y12 (85-208 PRU) a $\quad 136.9 \pm 84.7$

PPI proton pump inhibitor, MDRD-eGFR Modification of Diet in Renal Disease- estimated Glomerular Filtration Rate, NSAIDs non-steroidal antiinflammatory drugs, SSRIs selective serotonin reuptake inhibitors, $P C /$ percutaneous coronary intervention, $D E B$ drug-eluting balloon, $P O B A$ plain old balloon angioplasty, DES drug-eluting stent, $B M S$ bare metal stent $C A B G$ coronary artery bypass graft, DOAC direct oral anticoagulants, VKA vitamin $\mathrm{K}$ antagonist, $L M W H$ low molecular weight heparin

${ }^{\mathrm{a}}$ missing in 6 patients; ${ }^{\mathrm{b}}$ missing in 3 patients; ${ }^{\mathrm{C}}$ missing in 11 patients; ${ }^{\mathrm{d}}$ missing in 8 patients; ${ }^{\mathrm{e}}$ missing in 9 patients; ${ }^{\mathrm{f}}$ Triple therapy consists of a P2Y12 inhibitor plus aspirin plus anticoagulants (VKA, DOAC, LWMH); 9 in 364 patients not on anticoagulants (VKA, DOAC, LMWH); ${ }^{\mathrm{h}}$ cut-off values according to consensus documents [13-15] 
Table 3 Bleeding events and ischaemic events during follow-up

\begin{tabular}{|c|c|c|c|c|}
\hline Bleeding endpoint & Cumulative $(n=524)$ & T1 visit $(n=524)$ & T2 visit ${ }^{\mathrm{b}}(n=456)$ & T3 $_{\text {visit }}{ }^{\mathrm{b}}(n=420)$ \\
\hline Any bleeding & $254(48.5)$ & $147(28.1)$ & $135(29.6)$ & $82(19.5)$ \\
\hline \multicolumn{5}{|l|}{ Most severe bleeding } \\
\hline - BARC type 1 & $162(30.9)$ & $102(19.5)$ & $105(23.0)$ & $54(12.9)$ \\
\hline - BARC type 2 & $63(12.0)$ & $34(6.5)$ & $19(4.2)$ & $19(4.5)$ \\
\hline - BARC type 3 & $29(5.5)$ & $11(2.1)$ & $11(2.4)$ & $9(2.1)$ \\
\hline Total number of bleeding events ${ }^{a}$ & 442 & 188 & 159 & 95 \\
\hline - BARC type 1 & $332(75.1)$ & $139(73.9)$ & $126(79.2)$ & $67(70.5)$ \\
\hline - BARC type 2 & $75(16.9)$ & $36(19.1)$ & $20(12.6)$ & $19(20.0)$ \\
\hline - BARC type 3 & $35(7.9)$ & $13(6.9)$ & $13(8.2)$ & $9(9.5)$ \\
\hline Ischaemic event & $\begin{array}{l}\text { Cohort } \\
(n=524)\end{array}$ & & & \\
\hline No ischaemic events & $416(79.2)$ & & & \\
\hline $\begin{array}{l}\text { Major adverse cardiovascular event (myocardial infarction, stroke or all- } \\
\text { cause death) }\end{array}$ & $69(13.2)$ & & & \\
\hline Myocardial infarction & $36(6.9)$ & & & \\
\hline Stent thrombosis & $8(1.5)$ & & & \\
\hline Stroke & $13(2.5)$ & & & \\
\hline Death, all-cause & $23(4.4)$ & & & \\
\hline - Confirmed cardiovascular death ${ }^{c}$ & $6(1.1)$ & & & \\
\hline - Death (non-cardiovascular, unknown) & $17(3.2)$ & & & \\
\hline Coronary revascularisation & $37(7.1)$ & & & \\
\hline PAD with revascularisation & $17(3.2)$ & & & \\
\hline Venous thromboembolism & $3(0.6)$ & & & \\
\hline
\end{tabular}

\section{Follow-up}

The second and third study visit took place after a median of 201 days (187-217) and 369 (358-381) days post-PCI respectively. As shown in the flowchart of study inclusion and follow-up (Fig. 2), the cohort of patients with total follow-up for the entire treatment period, or until death as endpoint, consisted of 473 patients $(90.3 \%$ of the initial cohort).

\section{Bleeding events}

Approximately 1.5 month after PCI (T1), 147 patients (28.1\%) reported a total number of 188 bleeding events, $26 \%$ of which were BARC type 2 or 3 bleeding events (Tab. 3). Although the prevalence of bleeding symptoms had decreased to $19.5 \%$ in the period between T2 and T3 (compared with $28.1 \%$ and $29.6 \%$ between $\mathrm{PCI}$ and $\mathrm{T} 1$, and $\mathrm{T} 1$ and $\mathrm{T} 2$ respectively), the percentage of BARC type 2 or 3 amongst these bleeding events remained stable $(29.5 \%$ out of 95 bleeding events) as compared with T1.

After 12 months, 254 patients (48.5\%) had reported one or more BARC type 1-3 bleeding events. Most patients $(30.9 \%)$ had only reported mild bleeding (BARC type 1), for which no consultation or interventions were necessary. However, still 92 patients
(17.5\%) had experienced a BARC type 2 or 3 bleeding at any time point, necessitating consultation, diagnostic tests, interventions, blood transfusions and/or hospitalisation.

\section{Ischaemic events}

During one-year follow-up, 69 patients (13.2\%) had a major adverse cardiovascular event (Tab. 3 , supplementary Fig. 1); 36 patients with myocardial infarction, 8 patients with confirmed stent thrombosis, 13 patients with stroke and 23 of them had died during follow-up, of whom 6 patients with confirmed cardiovascular death.

\section{Medication switch}

The type, dosage or duration of P2Y12 inhibitor had to be adjusted in 78 patients (14.9\%) during 1-year follow-up due to bleeding episodes, recurrent ischaemic events, risk assessment, PFT results or side effects, or a combination of these. In another 33 patients (6.3\%), an unplanned change in anticoagulants and/or aspirin was necessary during follow-up (supplementary Table 1). 


\section{Publications about the cohort to date}

In a first publication, the agreement between different platelet function tests, as well as the factors influencing this agreement in vulnerable patients were assessed [10]. Results suggest that the agreement is only slight to moderate, and that PFTs are not interchangeable when determining the response to antiplatelet therapy. More recently, a small study was done focusing on possible strategies to optimise the agreement between the Multiplate and VerifyNow assay [11]. A study on the relationship between genetics (CYP2C19 metabolism) and results of PFTs in clopidogrel-treated patients was presented at the annual meeting of the European Society of Cardiology [12] and the full manuscript is currently in preparation, as well as manuscripts on the value of thrombin generation assays [13] and rotational thromboelastometry. Finally, an interim analysis presented at the Eurothrombosis Congress of the ESC Working Group on Thrombosis showed that using the previously proposed cut-off levels [14-16], PFTs performed at 1 month after PCI were not able to accurately predict bleeding complications in our high-risk population during a 1-year follow-up period [17].

\section{Discussion}

In this paper we present our well characterised cohort of high-risk patients on dual or triple antithrombotic therapy after PCI. This cohort will serve to answer several future research questions about predictors, safety and outcome of patients with multiple clinical risk factors on dual or triple antithrombotic therapy. The high incidence of both bleeding and ischaemic events, as well as the frequent need for medication adjustment during follow-up, indicates the need for strict monitoring of this patient group and illustrates challenges in optimal antithrombotic management.

In the past decade, several studies have shown that tailoring antiplatelet therapy based on PFTs does not prevent ischaemic and bleeding outcomes in the general PCI population [18-20]. With the recent advances in stent technology and broader use of potent P2Y12 inhibitors, thrombotic events have dramatically decreased, and consequently, prevention of bleeding complications has become a major goal [21-23]. Thus, as was also suggested in the recent expert consensus statement on platelet function testing for guiding P2Y12 inhibitor treatment, platelet function testing may play a more important role in a bleeding reduction strategy [22]. Indeed, randomised trials incorporating PFT results to de-escalate DAPT have shown promising results $[24,25]$. Reflecting these results, recent guidelines included a Class IIb recommendation for de-escalation of P2Y12 inhibition treatment guided by PFTs to be considered as an alternative DAPT strategy, especially for ACS patients deemed unsuitable for 12-month potent platelet inhibition
[1]. Building on this, such a risk assessment strategy might be even more beneficial when results of PFTs are combined with other variables in an algorithm [26]. This cohort can serve to optimise such risk assessment strategies.

\section{Future directions}

To further optimise the applicability of PFTs, adjustment of cut-off levels in various conditions (e.g. type of P2Y12 inhibitor, comorbidities) might be necessary, as the predictive capacity is currently limited. Our data could serve to adjust these cut-off levels for the different PFTs in specific, high-risk patient groups. Furthermore, the descriptive data, in combination with laboratory assays, genetics and bleeding questionnaires could be used for the construction of a multimarker risk prediction model. Current risk prediction models [27-30] are generally developed for the average PCI population, whereas a risk prediction model specifically developed for a high bleeding risk population currently does not exist [5]. At a later stage, such a model could be used in intervention studies stratifying therapy to high-risk patients. Collaboration with other research groups with comparable data is welcomed, and would be beneficial to further the prediction modelling plans. Besides optimisation of the combination and treatment duration of antithrombotic therapy in high-risk patients, new treatment options for high-risk patient populations are on the way. These recent advances not only involve new antithrombotic strategies (e.g. dual pathway inhibition [31]), but also anti-inflammatory drugs (e.g. canakinumab [32] or colchicine [33, 34]). These new therapies could be implemented and evaluated when continuing data collection on future cohorts of comparable high-risk patients in our centre.

\section{Strengths and limitations}

Strengths of this study are that it comprises a large prospective clinical cohort with detailed data and extensive laboratory testing. Particularly valuable is the comparison of three different PFTs with multiple agonists in a large cohort of high-risk patients. Another strength of our study is the detailed information on minimal bleeding events (BARC type 1), which were collected during the whole follow-up, although retrospectively from PCI until the first study visit. These minimal bleeding events often have an impact on patients' daily life, but as most studies only collect the bleeding events retrospectively, these BARC type 1 bleeding events could often not be reported. A limitation of our study is that due to rapid developments in stent technology, stronger platelet inhibition and guideline updates, the relatively long inclusion time of 5 years may have caused heterogeneity within the cohort. Moreover, due to the observational nature of the study, some patients decided to refrain from 
further hospital visits, chose to visit their regional cardiologist or general practitioner instead, or could not be contacted for study visits, leading to loss to follow-up in $9.7 \%$. Another limitation might be that the identification of risk factors for selection of high-risk patients was based on literature and expert consensus when initiating the study in 2014. Only recently, a consensus document from the Academic Research Consortium for High Bleeding Risk (ARCHBR) was published, presenting a consensus definition of patients at high bleeding risk [5]. Our risk factors show substantial overlap with this consensus definition; all minor criteria were included and out of the major criteria only recent or non-deferrable major surgery was not counted as a risk factor for inclusion in this cohort study. However, these data are retrievable when needed for analysis. Data on thrombocytopenia, active malignancy and chronic bleeding diathesis were structurally collected but not counted as a predefined risk factor in our cohort. In fact, due to concurrent research on platelet function and clotting factors, thrombocyte count $<100$ and known coagulation disorders were exclusion criteria in our study. However, the most important and reliable predictor of bleeding in patients with bleeding diatheses is a personal history of bleeding, which can be assessed with a bleeding questionnaire $[5,35]$, and this valuable information was collected in our study.

\section{Conclusion}

In this well characterised cohort of patients with multiple clinical risk factors treated with dual or triple antithrombotic therapy after PCI, we showed the high risk for both bleeding and ischaemic events. This challenges the treating physician to make a balanced decision on the optimal, individualised antithrombotic treatment strategy. Future results of this cohort study will serve to further expand the knowledge on the optimal treatment of these high-risk patients, and the implementation of patient characteristics and a wide range of laboratory tests to guide treatment decisions.

Acknowledgements We thank all patients for their commitment and all laboratory personnel and medical students who helped in any way.

Funding statement: this work was supported by the Thrombosis Expertise Centre at the Heart and Vascular Centre of Maastricht University Medical Centre (MUMC+) in the Netherlands. This research received no specific grant from any funding agency or commercial sector.

Author Contribution Contributors: RO, PM, MV, LV, YH and HC initiated the project. HC is the PI of the cohort. RO and MV coordinated the data entry. RO was responsible for data management, statistical analysis, and wrote the manuscript. YH coordinated all laboratory analyses. All authors revised the manuscript critically for important intellectual content and approved this version to be published.

\section{Declarations}

Conflict of interest R.H. Olie reports advisory and speakers' fees from Leo Pharma, Portola and Bayer, and travel grants form Sanofi, all outside the submitted work. A.W.J. van ' $t$ Hof reports grants from Medtronic, Abbott and Boehringer Ingelheim, and grants and speakers fees from AstraZeneca, outside the submitted work. J.M. ten Berg reports advisory, consulting and speakers' fees from AstraZeneca, Eli Lilly, Daiichi Sankyo, The Medicines Company, Accumetrics, Boehringer Ingelheim, BMS, Pfizer, Bayer and Ferrer, and received institutional research grants from ZonMw and AstraZeneca, all outside the submitted work. H. ten Cate reports research support from Bayer and Pfizer/BMS, participated in advisory boards for Bayer, Pfizer/BMS and Daiichi Sankyo, grants from Dutch Heart Foundation (CVON, CONTRAST), Eu-Marie Curie ITN (TAPAS, TICARDIO) and Regmed XB. HC is consultant for Alveron, shareholder in Coagulation Profile and is unpaid chairman of the Federation of Dutch Anticoagulation Clinics, all outside the submitted work. P.E.J. van der Meijden, L. Veenstra, Y.M.C. Henskens and M.J.A. Vries declare that they have no competing interests.

Ethical standards Approval for the observational cohort was obtained by the medical ethics committee of the Maastricht University Medical Centre (NL38767.068.11, METC number 11-2-096).

Open Access This article is licensed under a Creative Commons Attribution 4.0 International License, which permits use, sharing, adaptation, distribution and reproduction in any medium or format, as long as you give appropriate credit to the original author(s) and the source, provide a link to the Creative Commons licence, and indicate if changes were made. The images or other third party material in this article are included in the article's Creative Commons licence, unless indicated otherwise in a credit line to the material. If material is not included in the article's Creative Commons licence and your intended use is not permitted by statutory regulation or exceeds the permitted use, you will need to obtain permission directly from the copyright holder. To view a copy of this licence, visit http://creativecommons.org/licenses/by/4.0/.

\section{References}

1. Neumann FJ, Sousa-Uva M, Ahlsson A, et al. 2018 ESC/EACTS guidelines on myocardial revascularization. Eur Heart J. 2019;40:87-165.

2. Levine GN, Bates ER, Bittl JA, et al. 2016 ACC/AHA guideline focused update on duration of dual antiplatelet therapy in patients with coronary artery disease: a report of the American college of cardiology/American heart association task force on clinical practice guidelines: an update of the 2011 ACCF/AHA/SCAI guideline for percutaneous coronary intervention, 2011 ACCF/AHA guideline for coronary artery bypass graft surgery, 2012 ACC/AHA/ACP/AATS/PCNA/SCAI/STS guideline for the diagnosis and management of patients with stableischemic heart disease, 2013 ACCF/AHA guideline for the management ofST-elevation myocardial infarction, 2014 AHA/ACC guideline for the management of patients with non-STelevation acute coronary syndromes, and 2014 ACC/AHA guideline on perioperative cardiovascular evaluation and management of patients undergoing noncardiac surgery. Circulation. 2016;134:e123-55.

3. Wallentin L, Becker RC, Budaj A, et al. Ticagrelor versus clopidogrel in patients with acute coronary syndromes. NEngl J Med. 2009;361:1045-57. 
4. WiviottSD, BraunwaldE, McCabeCH, etal. Prasugrelversus clopidogrel in patients with acute coronary syndromes. NEngl J Med. 2007;357:2001-15.

5. Urban P, Mehran R, Colleran R, et al. Defining high bleeding risk in patients undergoing percutaneous coronary intervention: a consensus document from the academic research consortium for high bleeding risk. Circulation. 2019;40:2632-53.

6. Rodeghiero F, Tosetto A, Abshire T, et al. ISTH/SSC bleeding assessment tool: a standardized questionnaire and a proposal for a new bleeding score for inherited bleeding disorders. JThromb Haemost. 2010;8:2063-5.

7. Mehran R, Rao SV, Bhatt DL, et al. Standardized bleeding definitions for cardiovascular clinical trials: a consensus report from the bleeding academic research consortium. Circulation. 2011;123:2736-47.

8. Ndrepepa G, Schuster T, Hadamitzky M, et al. Validation of the bleeding academic research consortium definition of bleeding in patients with coronary artery disease undergoing percutaneous coronary intervention. Circulation. 2012;125:1424-31.

9. Thygesen K, Alpert JS, Jaffe AS, et al. Third universal definition of myocardial infarction. Eur Heart J. 2012;33:2551-67.

10. Vries MJ, Bouman HJ, Olie RH, et al. Determinants of agreement between proposed therapeutic windows of platelet function tests in vulnerable patients. Eur HeartJ Cardiovasc Pharmacother. 2017;3:11-7.

11. Hulshof AM, Vries M, Verhezen P, et al. The influence of prostaglandin E1 and use of inhibitor percentage on the correlation between the multiplate and verifynow in patients on dual antiplatelet therapy. Platelets. 2020; https://doi.org/10.1080/09537104.2020.1754378.

12. Hensgens RRK, Olie RH, Henskens YMC, Wijnen PAHM. P5733 comparison of three different platelet function tests in patients on P2Y12 inhibitors in correlation to genetic background. Eur Heart J. 2018; https://doi.org/10.1093/ eurheartj/ehy566.P5733.

13. de Breet CPDM, Zwaveling S, Vries MJA, et al. Thrombin generation as a method to identify the risk of bleeding in high clinical-risk patients using dual antiplatelet therapy. Front Cardiovasc Med. 2021;8:679934.

14. Tantry US, Bonello L, Aradi D, et al. Consensus and update on the definition of on-treatment platelet reactivity to adenosine diphosphate associated with ischemia and bleeding. J Am Coll Cardiol. 2013;62:2261-73.

15. Kerneis M, Silvain J, Abtan J, et al. Switching acute coronary syndrome patients from prasugrel to clopidogrel. JACC Cardiovasc Interv. 2013;6:158-65.

16. Bonello L, Tantry US, Marcucci R, et al. Consensus and future directions on the definition of high on-treatment platelet reactivity to adenosine diphosphate. J Am Coll Cardiol. 2010;56:919-33.

17. OlieRH, Geelen LWG, de GreefB, etal. Can plateletreactivity predict bleeding complications in a specifically vulnerable patient group? A comparison of three platelet function tests. ESC EuroThrombosis abstract book. 2018.

18. Collet JP, Cuisset T, Range G, et al. Bedside monitoring to adjust antiplatelet therapy for coronary stenting. N Engl J Med. 2012;367:2100-9.

19. Price MJ, Berger PB, Teirstein PS, et al. Standard- vs high-dose clopidogrel based on platelet function testing after percutaneous coronary intervention: the GRAVITAS randomized trial. JAMA. 2011;305:1097-105.

20. Trenk D, Stone GW, Gawaz M, et al. A randomized trial of prasugrel versus clopidogrel in patients with high platelet reactivity on clopidogrel after elective percutaneous coronary intervention with implantation of drug-eluting stents: results of the TRIGGER-PCI (testing platelet reactivity in patients undergoing elective stent placement on clopidogrel to guide alternative therapy with prasugrel) study. JAm Coll Cardiol. 2012;59:2159-64.

21. MoonJY, Franchi F, Rollini F, Angiolillo DJ.Evolution of coronary stent technology and implications for duration of dual antiplatelet therapy. Prog Cardiovasc Dis. 2018;60:478-90.

22. Sibbing D, Aradi D, Alexopoulos D, et al. Updated expert consensus statement on platelet function and genetic testing for guiding $\mathrm{P} 2 \mathrm{Y} 12$ receptor inhibitor treatment in percutaneous coronary intervention. JACC Cardiovasc Interv. 2019;12:1521-37.

23. Simonsson M, Wallentin L, Alfredsson J, et al. Temporal trends in bleeding events in acute myocardial infarction: insights from the SWEDEHEART registry. Eur Heart J. 2019;41:833-43.

24. Cuisset T, Deharo P, Quilici J, et al. Benefit of switching dual antiplatelet therapy after acute coronary syndrome: the TOPIC (timing of platelet inhibition after acute coronary syndrome) randomized study. Eur Heart J. 2017;38:3070-8.

25. Sibbing D, Aradi D, Jacobshagen C, et al. Guided deescalation of antiplatelet treatment in patients with acute coronary syndrome undergoing percutaneous coronary intervention (TROPICAL-ACS): a randomised, open-label, multicentre trial. Lancet. 2017;390:1747-57.

26. Vries MJ, van der Meijden PE, Henskens YM, et al. Assessment of bleeding risk in patients with coronary artery disease on dual antiplatelet therapy. A systematic review. Thromb Haemost. 2016;115:7-24.

27. Costa F, van Klaveren D, James S, et al. Derivation and validation of the predicting bleeding complications in patients undergoing stent implantation and subsequent dual antiplatelet therapy (PRECISE-DAPT) score: a pooled analysis of individual-patient datasets from clinical trials. Lancet. 2017;389:1025-34.

28. Raposeiras-Roubin S, Faxen J, Iniguez-Romo A, et al. Development and external validation of a post-discharge bleeding risk score in patients with acute coronary syndrome: the BleeMACS score. Int J Cardiol. 2018;254:10-5.

29. Baber U, Mehran R, Giustino G, et al. Coronary thrombosis and major bleeding after PCI with drug-eluting stents: risk scores from PARIS. JAm Coll Cardiol. 2016;67:2224-34.

30. Ducrocq G, Wallace JS, Baron G, et al. Risk score to predict serious bleeding in stable outpatients with or at risk of atherothrombosis. Eur Heart J. 2010;31:1257-65.

31. Eikelboom JW, Connolly SJ, Bosch J, et al. Rivaroxaban with or without aspirin in stable cardiovascular disease. NEngl J Med. 2017;377:1319-30.

32. Ridker PM, Everett BM, Thuren T, et al. Antiinflammatory therapy with canakinumab for atherosclerotic disease. NEngl J Med. 2017;377:1119-31.

33. Nidorf SM, Fiolet ATL, Mosterd A, et al. Colchicine in patients with chronic coronary disease. N Engl J Med. 2020;383:1838-47.

34. Tardif J-C, Kouz S, Waters DD, et al. Efficacy and safety of low-dose colchicine after myocardial infarction. N Engl J Med. 2019;381:2497-505.

35. Federici AB, Bucciarelli P, Castaman G, et al. The bleeding score predicts clinical outcomes and replacement therapy in adults with von Willebrand disease. Blood. 2014;123:4037-44. 